\title{
Effects of intake temperature and equivalence ratio on HCCI ignition timing and emissions of a 2-stroke engine
}

\begin{abstract}
Homogeneous charge compression ignition (HCCI) combustion, when applied to a gasoline engine, offers the potential for a noticeable improvement in fuel economy and dramatic reductions in NOx emissions. In this study, Computational Fluid Dynamic (CFD) is used coupled with detailed chemical mechanism (38 species and 69 reactions) for simulation of HCCI combustion of iso-octane and transitional flow inside the combustion chamber of a 2stroke engine. Results show that increasing the overall gas temperature significantly advances the HCCI combustion timing. Concerning the equivalence ratio, by increasing it the ignition timing has been advanced and the maximum cylinder pressure has been increased. When equivalence ratio increases to more than 0.5 , NOx emissions significantly increases and go beyond 1000 [ppm].
\end{abstract}

Keyword: 2-stroke engine; Equivalence ratio; HCCI; Ignition timing; Intake temperature 